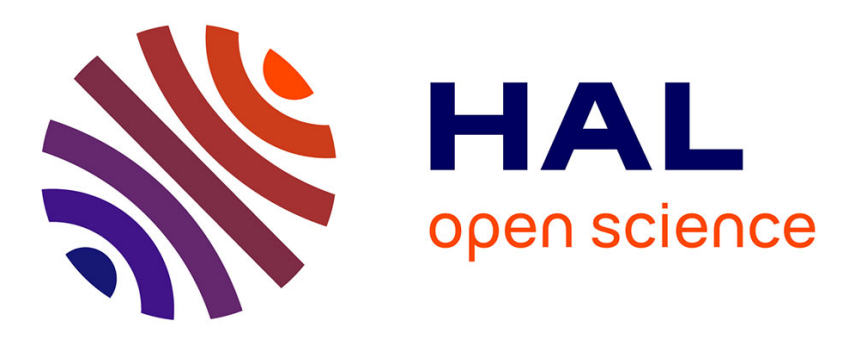

\title{
Production and Characterization of Quantum Nanostructures of Epitaxial Semiconductors
}

M. Berti, A. Drigo, M. Mazzer, A. Camporese, G. Torzo, G. Rossetto

\section{To cite this version:}

M. Berti, A. Drigo, M. Mazzer, A. Camporese, G. Torzo, et al.. Production and Characterization of Quantum Nanostructures of Epitaxial Semiconductors. Journal de Physique IV Proceedings, 1995, 05 (C5), pp.C5-1157-C5-1163. 10.1051/jphyscol:19955137 • jpa-00253835

\section{HAL Id: jpa-00253835 https://hal.science/jpa-00253835}

Submitted on 1 Jan 1995

HAL is a multi-disciplinary open access archive for the deposit and dissemination of scientific research documents, whether they are published or not. The documents may come from teaching and research institutions in France or abroad, or from public or private research centers.
L'archive ouverte pluridisciplinaire HAL, est destinée au dépôt et à la diffusion de documents scientifiques de niveau recherche, publiés ou non, émanant des établissements d'enseignement et de recherche français ou étrangers, des laboratoires publics ou privés. 


\title{
Production and Characterization of Quantum Nanostructures of Epitaxial Semiconductors
}

\author{
M. Berti, A.V. Drigo, M. Mazzer, A. Camporese*, G. Torzo* and G. Rossetto* \\ Unità INFM, Dipartimento di Fisica "G. Galilei", Università di Padova, Via Marzolo 8, 35131 Padova, \\ Italy \\ * ICTIMA-CNR, Corso Stati Uniti, 35127 Padova, Italy
}

\begin{abstract}
An experimental study has been performed using RBS and AFM characterization on InP islands grown by MOVPE on GaAs substrate, aiming to understand the influence of the growth parameters on the size distribution of the nanostructures. In the temperature range $580 \div 650{ }^{\circ} \mathrm{C}$ the total amount of deposited InP is independent of temperature which, on the contrary, affects the morphology of the growing islands. This work is part of a broader investigation on the feasibility of self organized growth to obtain nanosized semiconductor islands (Quantum Dots) by exploiting the mismatch-induced strain between substrate and epilayer in MOVPE deposition. In particular our data on the islands size are in very good agreement with preliminary indications of analytical and numerical models on the minimization of the total energy of the island-substrate system.
\end{abstract}

\section{INTRODUCTION}

In the last few years a great effort has been devoted to the study of low dimensional semiconductor structures. The reduction of the dimensionality causes several changes in the electronic and excitonic wave functions and these features can be used, at least in principle, to produce novel microelectronics and optical devices. At present the heteroepitaxial growth techniques are able to produce very well defined layers (Quantum Wells) exhibiting quantum confinement in one dimension, which are now currently used for device production. On the contrary, the technology of devices which could give 2D confinement (Quantum Wires) or 3D confinement (Quantum Dots) is not yet well defined. In particular quantum dots have been widely studied for their electron and exciton confinement, but a strong debate is still open on the best way of producing them.

Several technological approaches have been suggested including the use of patterned substrates (1), growth on vicinal surfaces (2) and various ways of self organization of the nanostructures $(3,4)$.

One of the most important parameters to be controlled is the quality of the interface between the islands and the substrate and to this purpose the self organized growth should give good results. Nevertheless the nanostructures must have a reproducible size and a uniform distribution over the substrate, and this goal can be attained only with a careful and systematic study of the growth conditions supported by theoretical and phenomenological modelization of the process. In fact the epitaxial growth of an overlayer onto a substrate proceeds via island formation only if a high lattice mismatch between the two structures is present. The knowledge of the conditions required for the start of island nucleation and successive growth can be obtained by studying the elastic deformation of the quantum dots - substrate system and the 
consequent equilibrium configuration of the structure. To this purpose theoretical works including analytical and numerical approaches are presently under study (5) and they will be published elsewhere.

In the present work the influence of the MOVPE growth parameters on the InP islands formation on a GaAs substrate is described. The best conditions to obtain islands with a small size and a uniform distribution are discussed.

\subsection{Experimental}

We have grown InP islands over (100) GaAs substrate using Trimethylindium (Epichem) and Phosphine (Ucar electronic grade) as precursors and the carrier gas was Pd-purified $\mathrm{H}_{2}$. All growth experiments have been performed in a standard LP-MOVPE reactor (AIXTRON AIX 200) with a rectangular reaction chamber and a carbon susceptor heated by IR lamps. The organoindium source (TMI) was thermoregulated at $17^{\circ} \mathrm{C}$. The total pressure in the reactor was $20 \mathrm{mbar}$, the gas velocity $2.3 \mathrm{~m} / \mathrm{sec}$ (calculated for room temperature conditions), the growth temperatures $\mathrm{T}_{\mathrm{g}}$ were 580,610 and $650^{\circ} \mathrm{C}$ and for each temperature we tried different growth speed for three different growth times $\left(\mathrm{t}_{\mathrm{g}}\right): 5,15$ and 30 seconds. The (nominal) growth rate value $\mathrm{v}_{\mathrm{g}}$ is determined by the $\mathrm{H}_{2}$ flow through the TMI bubbler, and it was calculated from the measured thicknesses of several homoepitaxial InP layers: the nominal growth rate corresponding to a $\mathrm{H}_{2}$ flux of $50 \mathrm{scc} / \mathrm{min}$ is $0.8 \mu \mathrm{m} / \mathrm{h}$.

Rutherford Backscattering Spectrometry (RBS) was used in order to measure the total amount of deposited InP, the maximum thickness of the islands and the fraction of the substrate covered by the nanostructures.

The measurements were performed at the AN2000 and CN accelerators at the Laboratori Nazionali di Legnaro (Padova-Italy) by using a $2 \mathrm{MeV} \mathrm{He}^{+}$beam. The measurements were performed in a conventional, normal incidence, geometry with a Si surface barrier detector placed at a scattering angle of $170^{\circ}$ with respect to the beam direction. The details of the analysis procedure are discussed elsewhere (6). A few samples were analyzed with a new depth-enhancing experimental set-up described in ref. (7).

A first 2D-morphology test of the samples was performed taking SEM micrographs with a XL40 model ( $\mathrm{LaB}_{6}$ source) Philips microscope.

The 3D surface morphology was investigated using an AFM (Park Scientific Instruments, model CP Autoprobe) in "contact mode".

\subsection{Results and discussion}

The total InP dose deposited on the samples was measured with the aid of RBS technique. Figure 1 shows the InP dose as a function of the deposition time for the samples grown at $\mathrm{T}=580^{\circ} \mathrm{C}$. The three symbols are respectively for the samples grown with a $\mathrm{H}_{2}$ flux of $50 \mathrm{scc} / \mathrm{min}$ (squares), $100 \mathrm{scc} / \mathrm{min}$ (circles) and $157 \mathrm{scc} / \mathrm{min}$ (triangles). The error bars are smaller than the symbols size in the graph. The deposited dose is shown to follow a linear trend with time. The same behaviour has been observed for the samples grown at different temperatures. Figure 2 shows the total InP dose measured for the samples grown at $\mathrm{T}=580^{\circ} \mathrm{C}$ as a function of the indium precursor flux (that is proportional to the growth rate $v_{\mathrm{g}}$ ). The three symbols are respectively for the samples grown for 5 seconds (circles), 15 seconds (triangles) and 30 seconds (squares). Also in this case a quasi linear trend of the dose versus flux is obtained. 


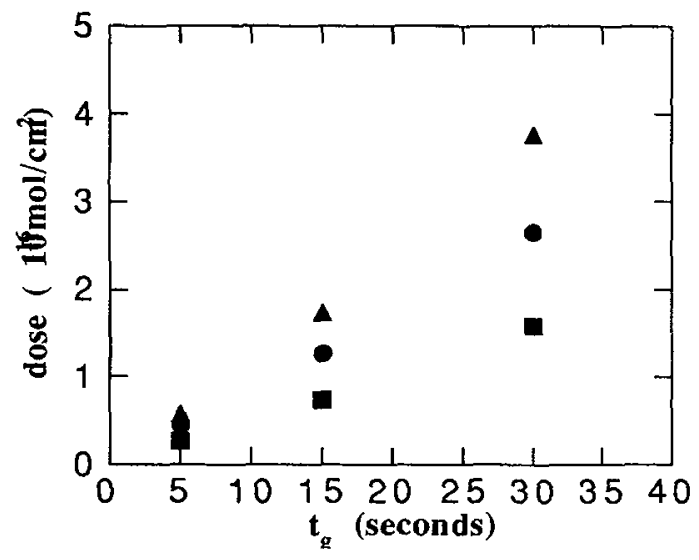

Figure 1: Dose of In vs growth time

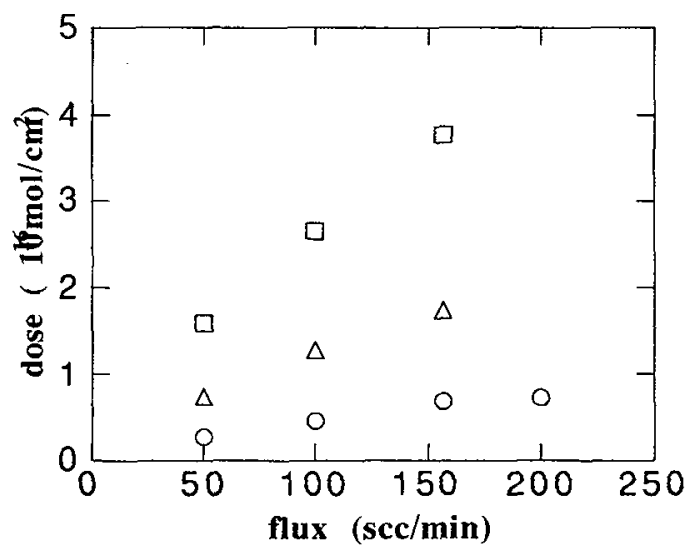

Figure 2: Dose of In vs $\mathrm{H}_{2}$ flux

The data of figures 1 and 2 suggest that the parameter which controls the total deposited material should be the product of Flux $\times$ Time.

The total deposited dose as a function of Flux $\times$ Time is reported in figure 3. Full circles refer to samples grown at $\mathrm{T}=580^{\circ} \mathrm{C}$, whereas open circles refer to samples grown at $\mathrm{T}=610^{\circ} \mathrm{C}$. The straight line is drawn only to guide the eye.

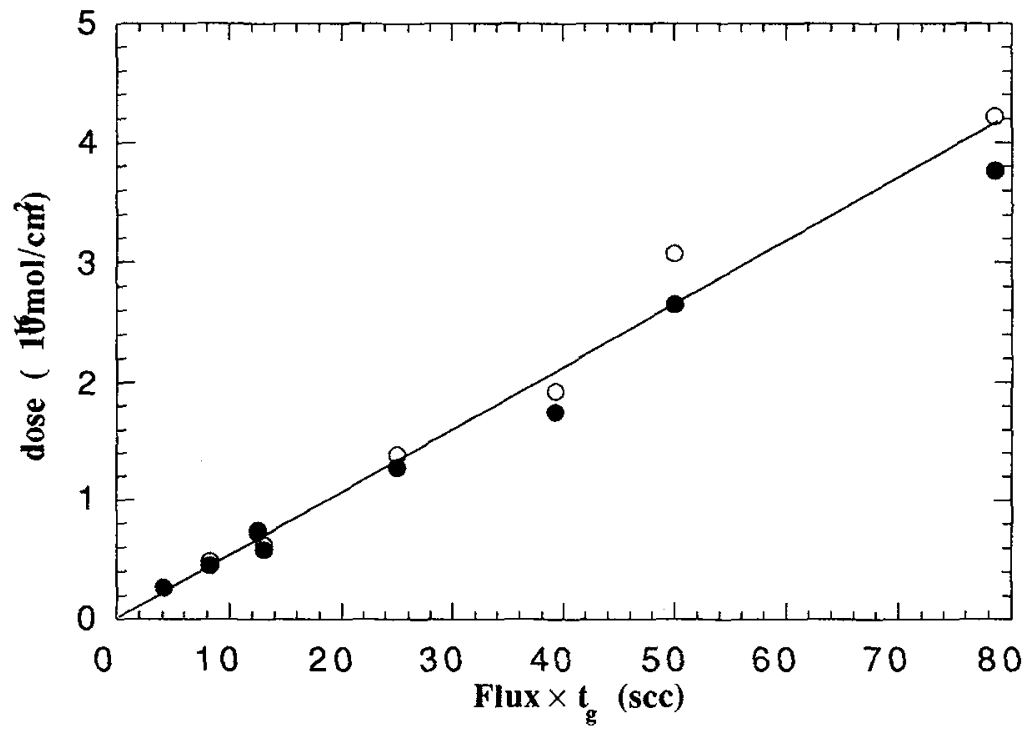

Figure 3: measured indium dose versus integrated flux of the TMI line.

The data of figure 3 indicate that the main parameter which controls the deposition is mass transport, suggesting that, independently of the growth temperature, the recipe to obtain a sample with a given $\operatorname{In} P$ dose is to maintain constant the product Flux per Time.

From RBS spectra the fraction of the surface covered by the growing islands has been also measured. The coverage fraction is shown in figure 4 for $\mathrm{T}=580^{\circ} \mathrm{C}$ (full circles) and for $\mathrm{T}=610^{\circ} \mathrm{C}$ (open circles). 


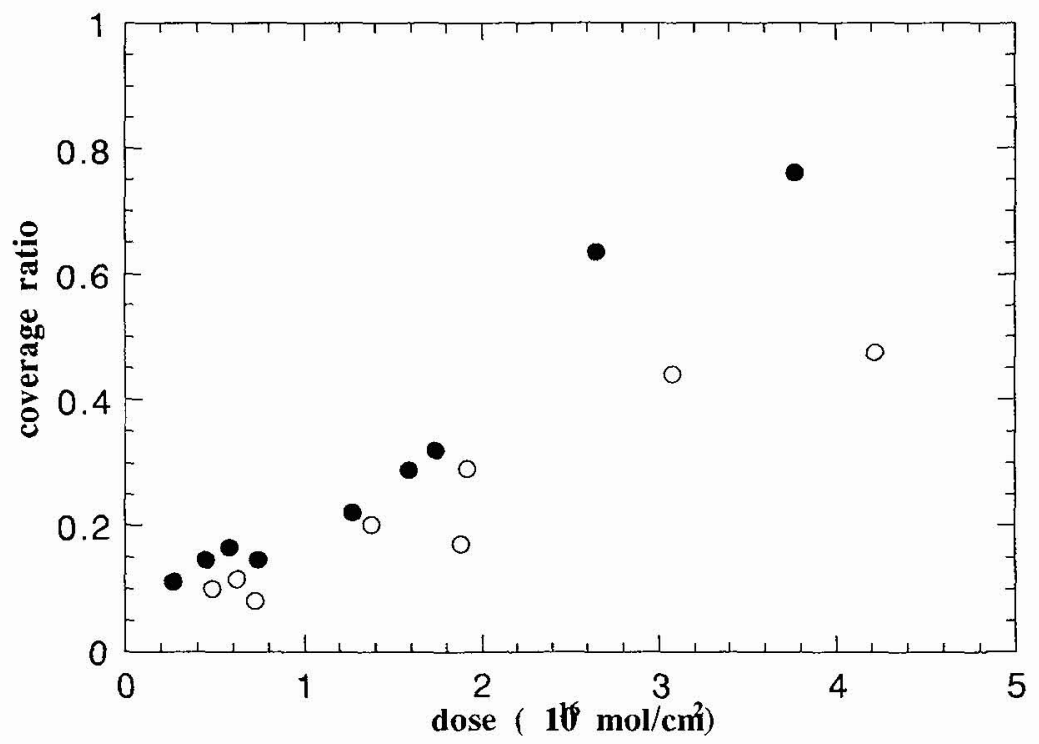

Figure 4: Fraction of the GaAs substrate covered by InP versus In dose

For the same deposited InP dose the surface covered fraction is always greater at $\mathrm{T}=580^{\circ} \mathrm{C}$ than at $\mathrm{T}=610^{\circ} \mathrm{C}$, being almost equal for small deposited doses. This fact implies that even if the total deposited material is controlled by a mass transport mechanism, surface energy, which strongly depends on temperature, mainly controls the island size. The greater surface coverage observed for the samples grown at lower temperatures is consistent with an average island size increasing with temperature. This is confirmed by the SEM analysis: in figure 5 are shown the micrographs of three samples grown for $\mathrm{tg}_{\mathrm{g}}=5$ seconds with $v_{\mathrm{g}}=0.8 \mu \mathrm{m} / \mathrm{h}$ at $\mathrm{T}_{\mathrm{g}}=580,610$ and $650^{\circ} \mathrm{C}$ respectively.

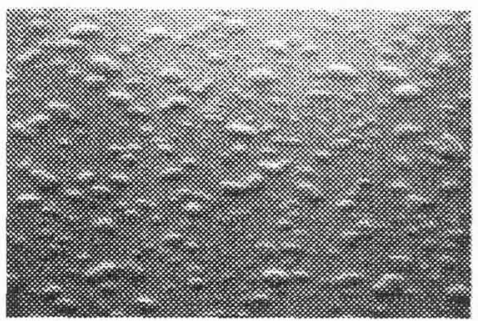

$$
\mathrm{T}_{\mathrm{g}}=580^{\circ} \mathrm{C}
$$

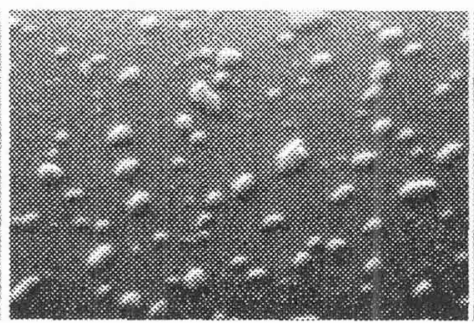

$\mathrm{T}_{\mathrm{g}}=610^{\circ} \mathrm{C}$

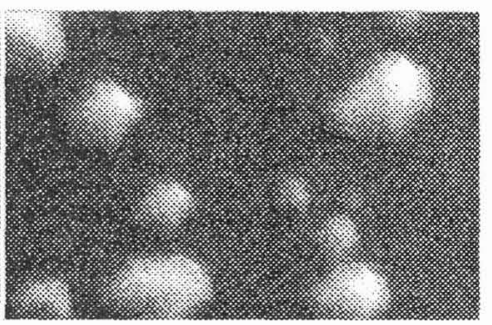

$\mathrm{T}_{\mathrm{g}}=650^{\circ} \mathrm{C}$

Figure 5: SEM micrographs of samples grown at different temperatures (picture dimensions: $4.5 \times 3.5 \mu \mathrm{m}$ )

SEM measurements may only provide 2D pictures of the sample surface: the "shadows" in figure 5 are produced by tilting the sample with respect to the electron beam, but no height profile may be calculated from the gray-scale values of the pixels in these images. On the other hand images taken with AFM allow direct measurements of both the island lateral size and height.

In figure 6,7 and 8 we report AFM images of samples grown for different times with the lowest values of growth rate and temperature, to show the time evolution of the InP nanostructures. 


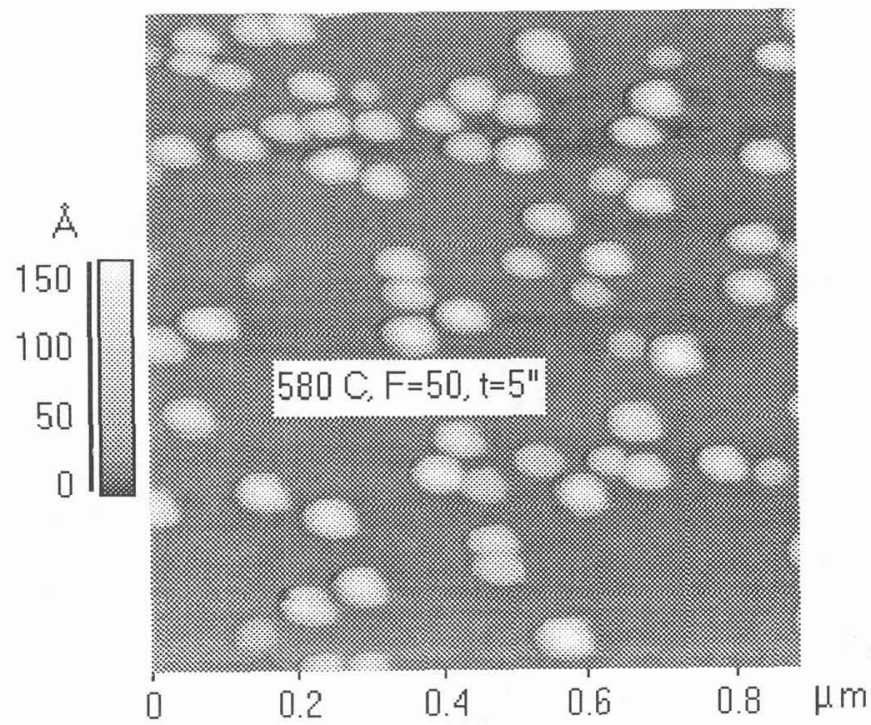

Figure 6: AFM Top View of a sample grown at $T_{g}=580^{\circ} \mathrm{C}$ with $v_{g}=0.8 \mu \mathrm{m} / \mathrm{h}$ for $\mathrm{t}_{\mathrm{g}}=5^{\prime \prime}$.
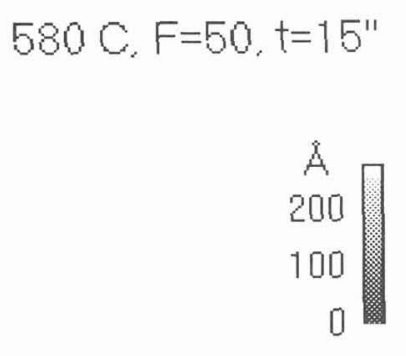

\section{Height. Profile}

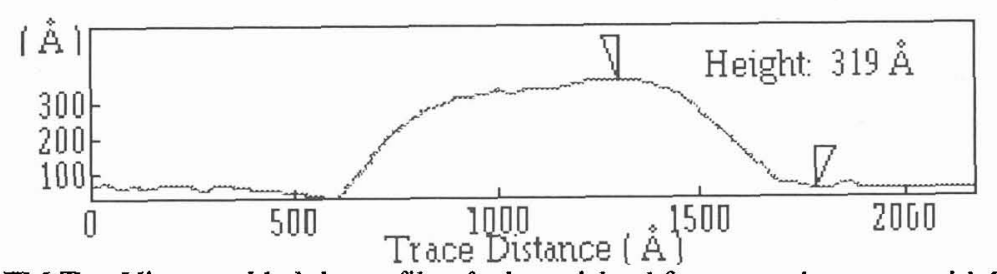

Figure 7: AFM Top View, and height profile of a large island for a sample grown with $\mathrm{T}_{\mathrm{g}}=580^{\circ} \mathrm{C}$, $v_{\mathrm{g}}=0.8 \mu \mathrm{m} / \mathrm{h}$ and $\mathrm{tg}_{\mathrm{g}}=15^{\prime \prime}$

At this low growth temperature many small and round-shaped islands are mixed with larger and faceted structures. By increasing the amount of deposited InP the number and the dimensions of the larger structures increase. Nevertheless a (decreasing) population of smaller islands was always observed. The lateral size and the height of these smaller islands exhibits a narrow distribution around the average values of $60 \mathrm{~nm}$ in lateral size and $12 \mathrm{~nm}$ in height. 


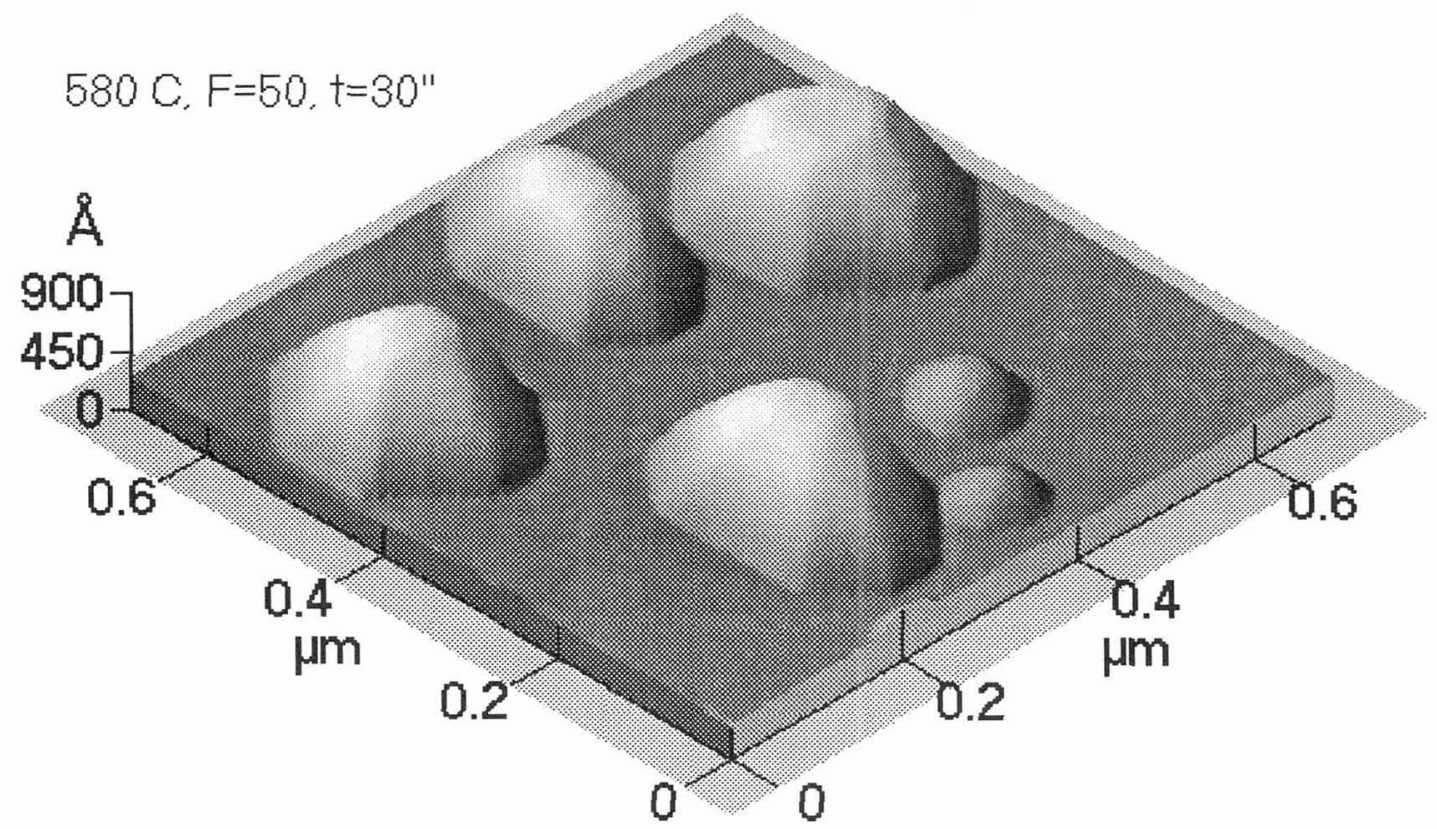

Figure 8: AFM 3D image of a sample grown at $\mathrm{T}_{\mathrm{g}}=580^{\circ} \mathrm{C}$ with $\mathrm{v}_{\mathrm{g}}=0.8 \mu \mathrm{m} / \mathrm{h}$ for $\mathrm{t}_{\mathrm{g}}=30$ seconds.

As for AFM image analysis care must taken in quantifying the lateral dimensions of the islands in those samples in which large islands and high surface coverage are contemporarily measured. In fact, in this case, the convolution of the dimensions of the probing tip with the surface corrugation could give misleading results. Nevertheless, in samples with well separated islands (i.e. low surface coverage) this source of error is substantially reduced. In these samples a systematic evaluation of the height to base diameter ratio was performed obtaining a mean value of about $20 \%$ which is in good agreement with the theoretical predictions of the models (5) which indicate for the same ratio a value of $17 \div 18 \%$. The models predict that once this value is reached the atoms migration towards the top of the islands is no more favoured and they tend to increase their lateral size yielding elongated shapes and faceting, in order to maintain surface energy minimization.

\section{Conclusions}

We have proven that in our MOVPE growing conditions the epitaxial growth of $\mathrm{InP} / \mathrm{GaAs}$ system. initially proceeds via island formation, and the parameter controlling the amount of deposited material is the product Flux $\times$ Time, independently of the growth temperature. Temperature, however, is the parameter which controls the island size distribution and the coverage of the substrate. For low growth temperatures a rather homogeneous distribution of the island sizes and a high substrate coverage can be obtained. Moreover, by evaluating the height to base-size ratio of the smaller islands, we derived an experimental agreement with the theoretical models which assume a strain-relaxation driven mechanism for the onset of the transition from a semicircular (isotropic) shape to the elongated one.

This work is still in progress in order to obtain InP/GaAs islands of dimension suitable to produce quantum confinement, i.e. maximum height lower than $10 \mathrm{~nm}$ and base diameter less than $60 \mathrm{~nm}$. 


\section{Aknowledgements}

This work has been partially supported by Progetto Finalizzato "Materiali Speciali per Tecnologie Avanzate" of CNR. The authors are grateful to P. Guerriero for providing the SEM analysis.

\section{References}

1 R. Nötzel, J. Temmyo, H. Kamada, T. Furuta and T. Tamamura, Appl. Phys. Lett., 1994, $65(4), 457$

2 Y. Arakawa, Y. Nagamune, M. Nishioka and S. Tsukamoto, Semicond. Sci. Technol., 1993, 8,1082

3 J. Ahopelto, A. Atsushi Yamaguchi, K. Nishi, A. Usui and H. Sakaki, Jpn.J. Appl. Phys.,1993, $32, \mathrm{~L} 32$

4 J. Y. Marzin, J.M. Gérard, A. Izrael, D. Barrier and G. Bastard, Phys. Rev. Lett., 1994, 73 (5), 716

5 M. Mazzer and A.Giuliani, private communication.

6 M. Berti, A.V. Drigo, M. Mazzer, F. Romanato, L. Lazzarini, P. Franzosi, G.C. Salviati and D. Bertone, Mater. Sci. Eng., 1994, B28, 214

7 M. Berti, A.V. Drigo and G. Torzo, submitted for publication in "Microsc. Microanal. Microstructure" 